\section{EVENTS PROVIDE DIRECT ACCESS TO ANSWERS}

Health Education North West and the Wales Deanery have each partnered with Colgate Oral Health Network to host an event answering dental professionals' questions on what direct access means for them and how they can work together to further enhance patient care.

The first event was held at Old Trafford in Manchester and the second at the Millennium Stadium, Cardiff; both were significantly oversubscribed.

Each event was chaired by the local Director of Postgraduate Dental Education, Nicholas Taylor for Health Education Northwest and Jon Cowpe for Wales Deanery, and the presenters delivered an update on the implications of direct access in primary dental care. Current topical questions including the NHS GDS contract, NHS regulations, patient group directions, scope of practice for radiography, and 'how to make the financial model work' were also addressed. This was followed by facilitated group work considering various scenarios.

Delegate feedback indicated that the majority of attendees learnt a great deal and would as a result change their professional practice.

More events are planned for this autumn.

\title{
FIRST AESTHETIC ORTHODONTICS SOCIETY TO HOLD CONFERENCE
}

The newly-formed European Society of Aesthetic Orthodontics (ESA0) will hold its inaugural conference on 14 December at the Royal College of Obstetricians and Gynaecologists (RCOG).

Aalok Shukla, ESAO Vice President, contacted the $B D J$ and said: 'We would like dentists to understand more about how to incorporate aesthetic orthodontics into their practice safely and ethically'

According to the ESA0, over the last few years there has been 'an explosion in general dentists offering fixed or removable orthodontics to help adult patients resolve aesthetic issues they have with the alignment of their teeth (also known as shortterm orthodontics [STO])'. The ESAO feels that a lot of the training in such techniques for general dentists has been led by commercial companies promoting their products. The society aims to promote and showcase the treatment results of STO cases as a valid treatment option for adults who want to improve their smile but have declined the 'gold standard' of comprehensive orthodontic care, and at the same time educate general practitioners to provide correct, documented orthodontic assessments and provide full valid consent to safeguard the public.

The ESAO also intends to raise awareness amongst the public about aesthetic orthodontics.

For more information about ESAO and the conference visit http://esao.co.uk/event-registration.

\section{AUDIT OSCARS HELD AT BRISTOL DENTAL HOSPITAL}

The Clinical Audit \& Effectiveness study day was held at Bristol Dental Hospital on 26 June 2013, incorporating the 'Annual Bristol Dental Hospital Audit Oscars'.

The aim of the day was to highlight the potential for improving clinical practice through clinical audit and effectiveness, and gave students and staff, both clinical and non-clinical, the opportunity to compete for the 'Audit Oscar' prize.

The winning audit was entitled Histopathological diagnosis in oral medicine by Mr Alastair Hetherington. The runner up was Extraction of first permanent molars of poor prognosis in children - re-audit by Ms Louisa Rose and Ms Sophie Goodman.

The third place audit was Quality of laboratory prescriptions, edentulous special trays and wax occlusal rims - re-audit by Mr James Ban.

The day and Audit Oscar prizes were sponsored by Wesleyan Medical Sickness and The Dental Defence Union (DDU).

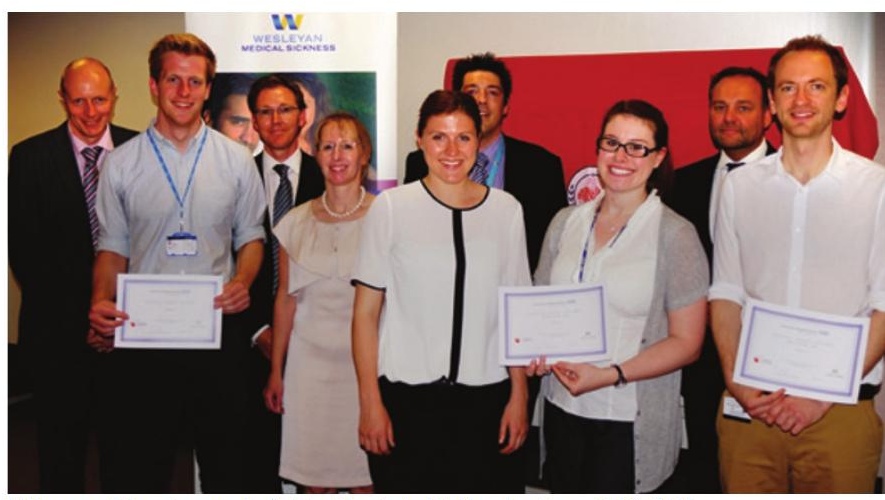

Winners (front row, I-r) Mr Alastair Hetherington, SHO (1 ${ }^{\text {st }}$ prize); Ms Louisa Rose and Ms Sophie Goodman, $4^{\text {th }}$ Year dental students ( $2^{\text {nd }}$ prize); Mr James Ban, StR in Restorative Dentistry ( $3^{\text {rd }}$ prize); Judges and Sponsors (back row, l-r) Mr Stuart Arnold (Wesleyan Medical Sickness); Mr Paul H. R. Wilson, (Consultant \&t Audit Lead); Professor Nicola West (Professor of Periodontology); Stuart Metcalfe (Clinical Audit and Effectiveness Manager), Mr John Makin (Dental Defence Union) 